Lep. Rer'. (I 966), 37, I, 41/43

\title{
Anterior Transposition of Ulnar Nerve in Leprosy
}

\author{
DR C. T. TILAK, м.B.B.s., Ex. I.м.s. \\ Medical Officer, Government Leprosy Subsidiary Centre, Kurnool, Andhra Pradesh, South India
}

The scientific meeting on Rehabilitation of the Disabled in Leprosy held at Vellore, Madras State, India, during November, i 960 under the auspices of the W.H.O. recommended studies for further clinical research on peripheral nerves in general and ulnar nerve in particular.

On the subject of clinical research on the ulnar nerve, the scientific session agreed 'that ulnar nerve transposition anterior to the medial epicondyle and deep to the flexor mass, as far lateral as the median nerve, should be considered at the carliest sign of palpable enlargement of trunk, of pain, or of weakness. Where competent surgical help is not available, consideration should be given to simple unroofing of the olecranon groove or division of the tough fibrous band, crossing the nerve, where it leaves the olecranon groove. In the rare instances, where solitary lesions appear in major nerve trunks, consideration should be given to excision of the lesion as soon as it is quiescent with end to end anastomosis.'

Mention may be made of other peripheral nerves commonly affected in leprosy like the median, radial, lateral popliteal, posterior tibial and branches of the facial nerve. These nerves are not usually displaced. On the other hand, the ulnar nerve is transferred to a new anatomical bed. This is a distinguishing feature characteristic of ulnar nerve surgery and is mandatory.

Common to most of the sites of involvement in peripheral nerves are:

(a) A superficial position.

(b) Liability to trauma and pressure.

(c) Proximity to bones and tendons.

(d) Tendency to stretch on movement of joints.

(e) A 'free lateral play' as in ulnar nerve.

(f) Fibrous bands and tunnels distal to point of involvement.

(g) Temperature lower than body temperature.
SURGIGAL ANATOMY OF ULNAR NERVE

\section{Certain considerations}

Anterior transposition of the ulnar nerve is a well established surgical procedure. Ingeneralsurgical practice, the indications are:

(a) Gun shot injuries, resulting in extensive lesions to the ulnar nerve.

(b) For all lesions in the post condylar groove (Traumatic neuritis).

Note-No mention is made of the ulnar nerve lesions in leprosy.

Of all the major peripheral nerves supplying the upper extremity the ulnar nerve is the most important as it innervates all the small muscles of the hand medial to the tendon of flexor pollicis longus. Besides, it also supplies both the heads of flexor carpi ulnaris and the medial half of the flexor digitorum profundus.

In the upper arm, at its middle, the nerve pierces the medial intermuscular septum, and accompanied by the long slender ulnar collateral artery, enters the posterior osteofacial compartment and descends along the medial head of triceps muscle being closely invested by its muscle fibres. No branches are given in the upper arm.

At the elbow it occupies the post condylar groove and under cover of the tough fibrous arch bridging the heads of origin of flexor carpi ulnaris. The bridge acts as a roof and the bony groove acts as floor, to which the nerve is adherent through loose areolar tissue.

The nerve then passes into the forearm between the heads of the flexor carpi ulnaris lying upon flexor digitorum profundus and under cover of flexor carpi ulnaris.

Thus the nerve is entirely posterior throughout. To transpose the nerve anteriorly the sharp tough fibrous barrier of the medial inter muscular septum has to be freely divided. During this division, the supratrochlear artery and its 
branches may be severed, as it lies close to the medial inter muscular septum.

The next step is the division of the tough fibrous arch to unroof the nerve. To free the nerve from its bony floor, blunt gauze dissection of the areolar tissue is necessary.

Occasionally the nerve supply to the olecranon head of the flexor carpi ulnaris is high up, short, stout and effectively anchors the nerve rendering free mobilisation impossible. The branch has then to be sacrificed.

The nerve thus freed, is mobilised and brought on to the medial epicondyle where a muscle bed is provided by the division of the flexor mass. Angulation, kinking and undue tension of the nerve are avoided in the process of embedding it.

\section{IS CUSSION}

The series of 12 cases, constitutes a small record. They are presented here, as 3 out of $\mathrm{I} 2$ operated turned out to be nerve abscess.

The analysis of ulnar nerve case reports is as follows :

(a) Secondary neuritis due to lepromatous leprosy $-3+\mathrm{I}=4$.

(b) Dimorphous $-\mathrm{I}+\mathrm{I}=2$.

(c) Mono-neuritis multiplex -2 .

(d) Solitary nerve abscess without any clinical skin involvement - I.

(e) Major tuberculoid - 3 (includes 2 nerve abscess).

Cochrane and Khanolker have mentioned that there has been no evidence of the existence of pure polyneuritic or neuritic-sub type of tuberculoid leprosy. It is admitted that in all forms of leprosy - tuberculoid, lepromatous or dimorphous - the patient may show, in addition to visible cutaneous lesions, signs of general neural involvement. When the infiltration of the bacilli have disappeared from the skin, the neural signs remain as residual lesions resulting in secondary polyneuritic type. Muir and others have long held that neuritic leprosy is a true ascending neuritis, and the work of Khanolkar has indicated that this is in all probability correct.

Be that as it may, the nerve enlargement must be considered as an expression of active tissue response, with a tendency to localise, and in rare instances abscess formation does occur. The abscess may be either single or miliary and multiple. It may be acute, sub-acute or chronic, and is usually chronic.

Local epidemiclogical factors: sub-type of the disease and age would appear to determine the incidence of abscess formation. This aspect is worthy of further elucidation. Also abscess formation in the ulnar nerve is more frequent than in other peripheral nerves. Mention may be made of Muir's three cases affecting the medial cutaneous nerve of the arm, the radial nerve and the ulnar nerve respectively.

'The remarkable thing about these three cases was that the lesions of the nerves affected were the only lesions discoverable in the body. Why abscesses should have formed in these cases it is difficult to say. Certainly it does not appear to be due to increased virulence of the causal organisms or to unusually low resistance of the tissues. Had that been so, then surely the disease would have shown manifestations in other parts of the body.'

\section{S U M M A R Y}

The directive principles as laid down in the WHO circular, in respect of emplacement of nerve in flexor muscle bed have been strictly adhered to.

The surgical importance of medial intermuscular septum, ulnar collateral and supra trochlear arteries and branches are stressed.

In the case series reported no resection of nerve trunk was done and hence no 'tunnelling' of flexor muscle mass.

The role of nerve stripping is ambiguous - no trial was given to this surgical manouvre.

Intra neural injections of Novocaine, Rhondase, Dexa-methasone and Priscol were restricted to mononeuritic cases and severe nerve trunk pain. Chymotrypsin was not tried owing to nonavailability. These therapeutic measures are at best conservative and palliative.

The pus was always sterile.

One case of sutureless skin surgery with adhesive strips is reported. The cosmetic results are gratifying.

Post-operative follow up have included specific therapy, combined with long acting Sulfas, active and passive movements with massage and gradual weight bearing under supervision. The patients have been periodically reviewed at monthly intervals and are psychologically satisfied. There has been no clinical evidence of 'dislocation' of the nerve in its new anatomical bed.
42

Leprosy Review 
In patients with paresis, atrophies and restriction in the mobility of joints, further development of these phenomena was discontinued.

Surgical intervention is the best method of prophylaxis of paralysis and deformity. This view expressed by Idris is shared by us.

\section{A GKNOWLEDGEMENT}

In conclusion I wish to thank the staff members of the Government Leprosy Subsidiary Centre, Kurnool, for their active interest and post-operative care of the patients. My particular thanks are also due to Sri M. Danaiah, Medico-social workers for his zeal and untiring efforts, Sri L. Ramaiah, B.A., for typing and to Dr C. Ramachandra Rao, M.B., B.s.sc., D.N. (Cal.), Chief District
Medical Officer of Health, Kurnool, for his help and permission to publish the article.

\section{R E F E R E N CES}

I GUnNingham, D. J. ( 1948 ). 'Upper Limb'. Cunninghams' Manual of Practical Anatomy, 129.

2 Cochrane, R. G. (I 959). 'Neuritic Leprosy'. Leprosy in Theory and Practice, ro, p. 136.

3 Dharmendra (i96o). 'Polyneuritic Type'. Notes on Leprosy, $\mathbf{I} 7$.

4 GREY TURNER, G. (I 955). 'Anterior Transposition of the Ulnar Nerve'. Modern Operative Surgery, $\mathbf{5 2 6}^{26}$.

5 IDRISOv, A. s. (1962). Experience with surgery on peripheral nerves in leprosy patients. Zdravookhr Kazakh, 22, pp. 8-I I.

6 ROGERS, L. and MUIR, E. (I925). 'The Lesions of Leprosy'. Leprosy, r94.

7 World Health Organisation Report (1960). Leprosy/ rehabilitation, 7, 12 . 